\title{
Inhibitory effects of Synurus excelsus and Weigela subsessilis on aldose reductase and HPLC-UV analysis of scopolin, scopoletin, and quercetin
}

\author{
Norman G. Quilantang ${ }^{1} \cdot$ Ju Sung Lee ${ }^{1} \cdot$ Seo Hyun Ryu ${ }^{2} \cdot$ Se Hoon Park ${ }^{2}$. \\ Jae Sang Byun ${ }^{2} \cdot$ Je Sung Chun ${ }^{2} \cdot$ Sonia D. Jacinto ${ }^{3} \cdot$ Sanghyun Lee $^{1}$
}

Received: 22 March 2018 / Accepted: 14 April 2018 / Published Online: 30 June 2018

(C) The Korean Society for Applied Biological Chemistry 2018

\begin{abstract}
The inhibition of aldose reductase (AR) has been shown to prevent the progression of the many complications associated with diabetic hyperglycemia. Several compounds purified from various plant sources have exhibited potent inhibition against AR. In this study, the inhibitory effects of the methanol extracts of the flowers of Synurus excelsus and Weigela subsessilis on AR were determined in vitro. Scopolin and scopoletin are coumarins isolated from the flowers of $S$. excelsus and W. subsessilis; and quercetin is a known AR inhibitor present in many flowers. To determine and quantify their presence in both plants, HPLC-UV analysis of all three compounds was performed. S. excelsus and $W$. subsessilis showed potent inhibition against $\mathrm{AR}$ having $\mathrm{IC}_{50}$ values of 0.17 and $0.14 \mu \mathrm{g} / \mathrm{mL}$ respectively. The concentration of scopolin in S. excelsus and W. subsessilis were 34.71 and 174.14 $\mathrm{mg} / \mathrm{g}$ extract, respectively. Scopoletin was detected in $S$. excelsus at $3.41 \mathrm{mg} / \mathrm{g}$ extract, whereas quercetin was not detected in both plants. This study shows that $S$. excelsus and $W$. subsessilis exhibited promising AR inhibitory effects and are both sources of coumarins.
\end{abstract}

Keywords Aldose reductase $\cdot$ Quercetin $\cdot$ Scopoletin $\cdot$ Scopolin - Synurus excelsus $\cdot$ Weigela subsessilis

Sanghyun Lee $(\triangle)$

E-mail: slee@cau.ac.kr

${ }^{1}$ Department of Integrative Plant Science, Chung-Ang University, Anseong 17546, Republic of Korea

${ }^{2}$ Seoul Science High School, Seoul 03066, Republic of Korea

${ }^{3}$ Institute of Biology, University of the Philippines, Diliman, Quezon 1101, Philippines

This is an Open Access article distributed under the terms of the Creative Commons Attribution Non-Commercial License (http://creativecommons. org/licenses/by-nc/3.0/) which permits unrestricted non-commercial use, distribution, and reproduction in any medium, provided the original work is properly cited.

\section{Introduction}

Aldose reductase (AR) is a cytosolic oxidoreductase that catalyzes the NADPH-dependent conversion of glucose to sorbitol [1]. AR is the rate-limiting enzyme of the polyol pathway, which is a metabolic pathway regarded as one of the key molecular mechanisms linked to the onset and progression of secondary diabetic complications (e.g., blindness, cardiovascular diseases, renal failure, and neurodegenerative disorders) [2]. Studies have shown that the inhibition of AR prevents the development of diabetic complications, thereby, making AR an attractive target for drug discovery [3-5]. Several synthetically produced AR inhibitors (ARIs) have shown promising results in animal models, however, they exhibit undesirable side effects or lesser efficacy during clinical trials [6]. Hence, there is an increased interest to identify novel and potent ARIs from natural sources because they offer safer alternative and potentially better results in treating and managing diabetic complications. For example, flavonoids, a class of polyphenolic compounds, are known to exhibit a variety of biological activities [7]. Particularly, quercetin, a flavonoid ubiquitously found in many flowers, is known to have strong inhibitory effects against AR [8].

Synurus excelsus (Asteraceae) and Weigela subsessilis (Caprifoliaceae) are perennial plants native to many East Asian countries such as Japan and Korea [9]. They are commonly grown as garden ornaments due to their beautiful foliage and inflorescence. Recent studies have shown that extracts from these plants are rich in bioactive compounds. Particularly, scopoletin and scopolin are coumarins isolated from the flowers of both these plants with various biological activities [10,11]. However, bioactive properties of $S$. excelsus and $W$. subsessilis are not fully explored.

Hence, this study aimed to identify the potential medicinal uses of both these plants. Particularly, we aimed to determine their in vitro inhibitory activity on AR obtained from rat lenses. Scopolin, scopoletin, and quercetin were also quantified by HPLC-UV. 


\section{Materials and Methods}

\section{Plant materials and animals}

The methanol $(\mathrm{MeOH})$ extracts of the flowers of $S$. excelsus and W. subsessilis were obtained from the Korea Plant Extract Bank. Seven-week-old Sprague-Dawley rats weighing 210-230 g were acquired from Core Tech Co. Ltd. (Pyeongtaek, Gyeonggi, Korea).

\section{Chemicals and apparatus}

Sodium phosphate buffer, potassium phosphate buffer, and $\mathrm{MeOH}$, were obtained from Samchun Pure Chemical Co. (Pyeongtaek, Korea). Dimethyl sulfoxide (DMSO), 3,3'-tetramethyleneglutaric acid (TMG), DL-glyceraldehyde, $\beta$-NADPH, and standard compounds (scopolin and scopoletin) were purchased from Sigma-Aldrich Chemicals (St. Louis, MO, USA). Quercetin was previously isolated from the flowers of Rhododendron mucronulatum for. albiflorum [12]. An Allegra X-30R refrigerated benchtop centrifuge (Beckman Coulter ${ }^{\mathrm{TM}}$, Indianapolis, IN, USA) and an Optizen 2120 UV spectrophotometer (Mecasys Co., Daejeon, Korea) were used for the ARI assay.

\section{Preparation of AR from rat lenses}

AR was prepared from rat lenses following a previously described protocol [13]. Lenses from healthy Sprague-Dawley rats were resected and homogenized in $0.5 \mathrm{~mL}$ of $0.1 \mathrm{M}$ sodium phosphate buffer ( $\mathrm{pH}$ 6.2), for each lens. The homogenate was centrifuged at $10,000 \mathrm{rpm}$ at $4^{\circ} \mathrm{C}$ for $20 \mathrm{~min}$, and the resulting supernatant was collected and used as an enzyme source.

\section{Measurement of ARI activity}

The ARI activity of the flower extracts was determined by spectrophotometrically measuring the decrease in NADPH absorbance at $340 \mathrm{~nm}$ for a period of $4 \mathrm{~min}$ with DL-glyceraldehyde as a substrate. The total volume of the assay solution was $1 \mathrm{~mL}$ and it was composed of the rat lens $\mathrm{AR}$, plant extract dissolved in DMSO, $25 \mathrm{mM}$ DL-glyceraldehyde, $1.6 \mathrm{mM}$ NADPH, $100 \mathrm{mM}$ sodium phosphate buffer and $100 \mathrm{mM}$ potassium phosphate buffer (pH 7.0). TMG was used as a positive control. The inhibitory activity of the samples is expressed as: $(\%)$ Inhibition $=$ (normal enzyme activity-inhibited enzyme activity)/normal enzyme activity. The $\mathrm{IC}_{50}$ values were determined from the least-squares regression line of the logarithmic concentrations plotted against residual activity. Three trials were performed for every sample.

\section{Standard and sample preparation for HPLC-UV analysis}

HPLC samples were prepared by dissolving $10 \mathrm{mg}$ of the flower extracts in $1 \mathrm{~mL} \mathrm{MeOH}$. Standard stock solutions $(1 \mathrm{mg} / \mathrm{mL})$ of scopolin, scopoletin, and quercetin were prepared in $\mathrm{MeOH}$. All samples were filtered through a $0.45-\mu \mathrm{m}$ filter prior to use.

\section{HPLC-UV analysis of scopoletin and scopolin}

The content of scopoletin and scopolin was measured with an
Table $1 \mathrm{IC}_{50}$ values for the inhibitory effects of the $\mathrm{MeOH}$ extracts of the flowers of $S$. excelsus and $W$. subsessilis on AR

\begin{tabular}{cccc}
\hline \hline Sample & $\begin{array}{c}\text { Concentration } \\
(\mu \mathrm{g} / \mathrm{mL})\end{array}$ & $\begin{array}{c}\text { Inhibition }^{\mathrm{a}} \\
(\%)\end{array}$ & $\begin{array}{c}\mathrm{IC}_{50} \mathrm{~b}^{\mathrm{b}} \\
(\mu \mathrm{g} / \mathrm{mL})\end{array}$ \\
\hline \multirow{3}{*}{ S. excelsus } & 10 & 92.82 & \\
& 1 & 62.2 & 0.17 \\
\hline \multirow{3}{*}{ W. subsessilis } & 0.1 & 47.37 & \\
& 10 & 94.4 & \\
& 0.1 & 73.6 & 0.14 \\
$\mathrm{TMG}^{\mathrm{c}}$ & 10 & 44.8 & \\
& 1 & 99.62 & \\
& 0.1 & 67.31 & 0.17 \\
\hline
\end{tabular}

anhibition is calculated as a percentage of the control value

${ }^{\mathrm{b}} \mathrm{IC}_{50}$ values were calculated from the least-squares regression line of the logarithmic concentrations plotted against the residual activity

${ }^{\mathrm{T}} \mathrm{TMG}$ was used as a positive control<smiles>COc1cc2ccc(=O)oc2cc1OC1OC(C)C(O)C(O)C1O</smiles>

(A)<smiles>COc1cc2ccc(=O)oc2cc1O</smiles>

(B)<smiles>O=c1c(O)c(-c2ccc(O)c(O)c2)oc2cc(O)cc(O)c12</smiles>

(C)

Fig. 1 Structures of scopolin (A), scopoletin (B), and quercetin (C)

Agilent HPLC system and an INNO $\mathrm{C}_{18}(4.6 \times 250 \mathrm{~mm}, 5 \mu \mathrm{m})$ column. The mobile phase used was composed of $0.5 \%$ acetic acid in water (solvent $\mathrm{A}$ ) and $\mathrm{MeOH}$ (solvent $\mathrm{B}$ ). The gradient elution program was as follows: $85 \% \mathrm{~A}$ at $0 \mathrm{~min}, 60 \% \mathrm{~A}$ at 25 $\mathrm{min}, 50 \% \mathrm{~A}$ at $40 \mathrm{~min}$, and maintained until $55 \mathrm{~min}$. The flowrate and injection volume were $1 \mathrm{~mL} / \mathrm{min}$ and $10 \mu \mathrm{L}$, respectively. The $\mathrm{UV}$ detector was set at $330 \mathrm{~nm}$.

\section{HPLC-UV analysis of quercetin}

An Agilent HPLC system was used for the analysis. Chromatographic separation was performed with a reverse-phase INNO $\mathrm{C}_{18}$ $(4.6 \times 250 \mathrm{~mm}, 5 \mu \mathrm{m})$ column. A gradient elution of $0.5 \%$ acetic acid in water: acetonitrile (90:10-50:50 for $50 \mathrm{~min}$ ) was followed. The flowrate and injection volume were $1 \mathrm{~mL} / \mathrm{min}$ and $10 \mu \mathrm{L}$, 
(A)

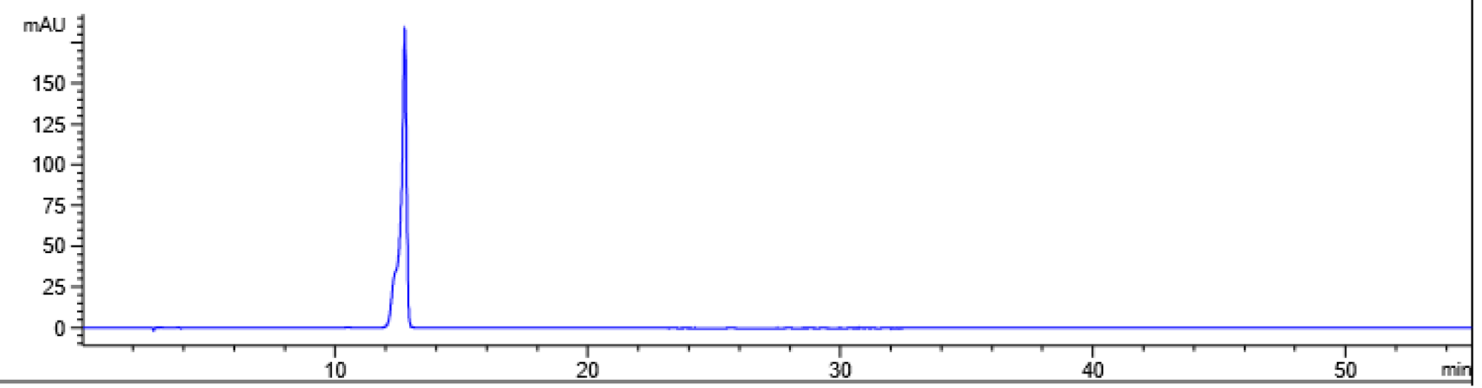

(B)

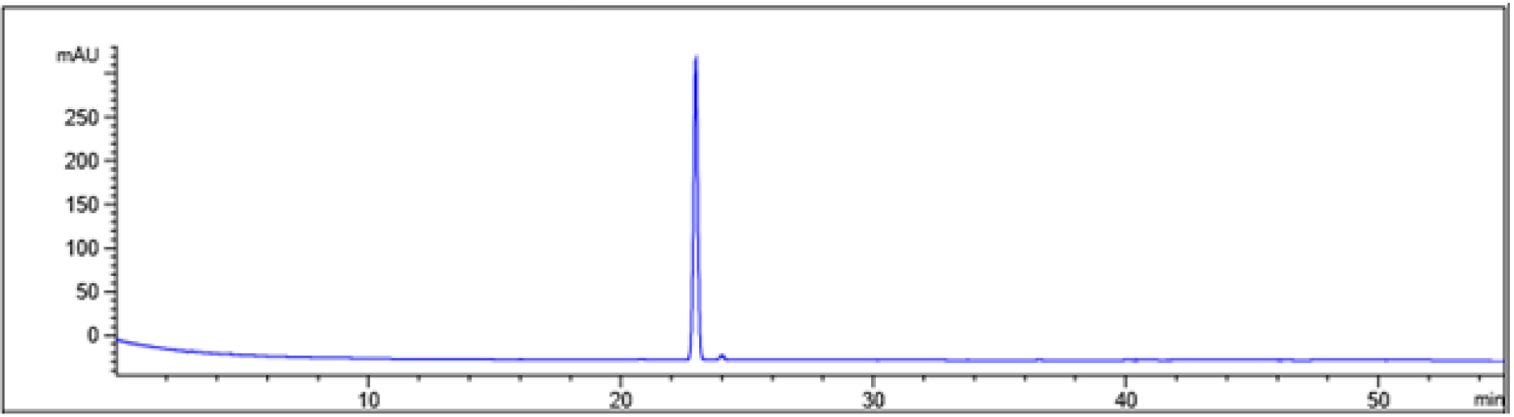

(C)

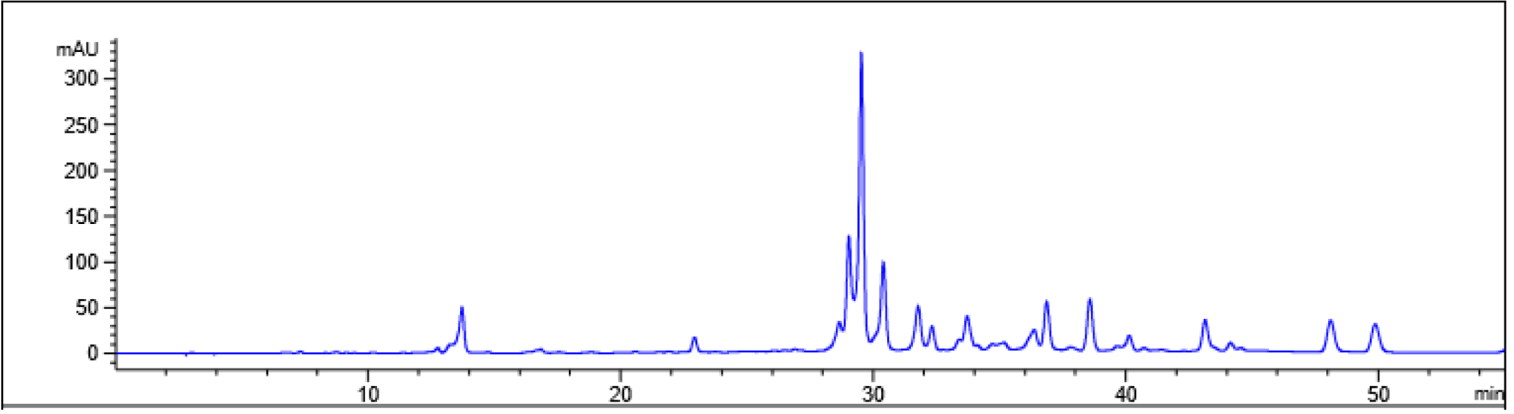

(D)

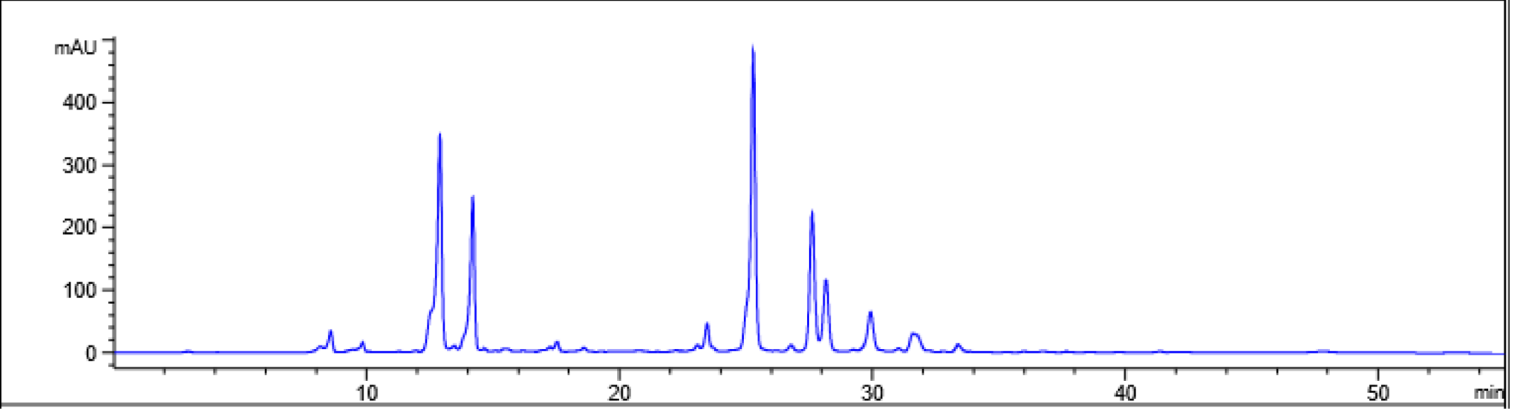

Fig. 2 HPLC chromatograms of scopolin (A), scopoletin (B), and the MeOH extracts of S. excelsus (C) and W. subsessilis (D)

respectively. The UV detector was set at $270 \mathrm{~nm}$.

\section{Calibration curve}

The working solutions used to construct calibration curves for scopolin, scopoletin, and quercetin were obtained by diluting the respective stock solutions to desired concentrations. The calibration curves were used to determine the content of each reference compound in the samples. Linearity was assessed based on the correlation coefficient $\left(r^{2}\right)$.

\section{Results and Discussion}

An increased activity of AR under chronic hyperglycemia leads to osmotic and oxidative stress in cells due to the accumulation of products of the polyol pathway (i.e., sorbitol and reactive oxygen species) and an imbalance in NADPH/NADH cofactors [14]. The secondary complications associated with diabetes have been postulated to be a consequence of prolonged oxidative stress as evident from the raised levels of oxidized DNA, proteins, and 
(A)

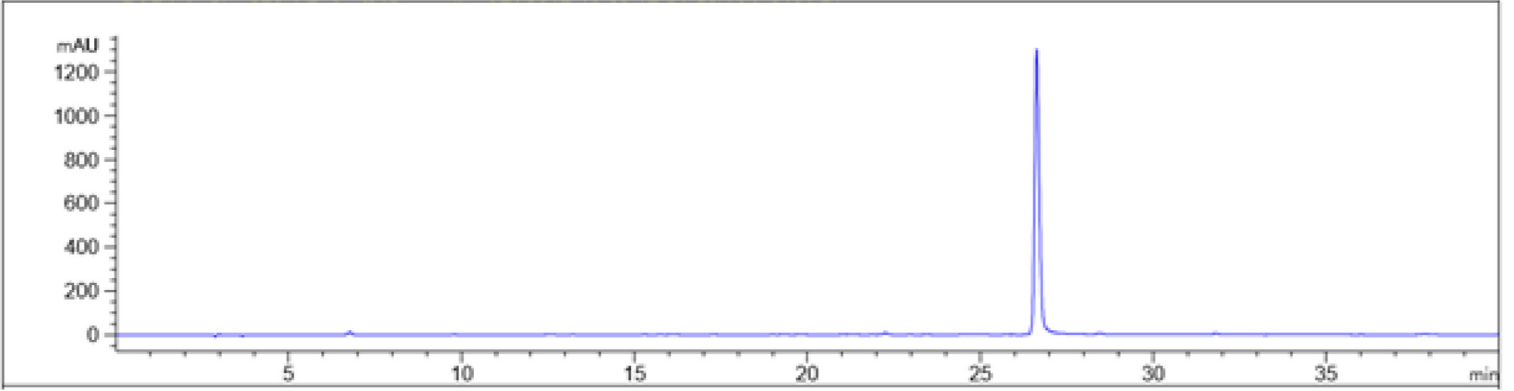

(B)

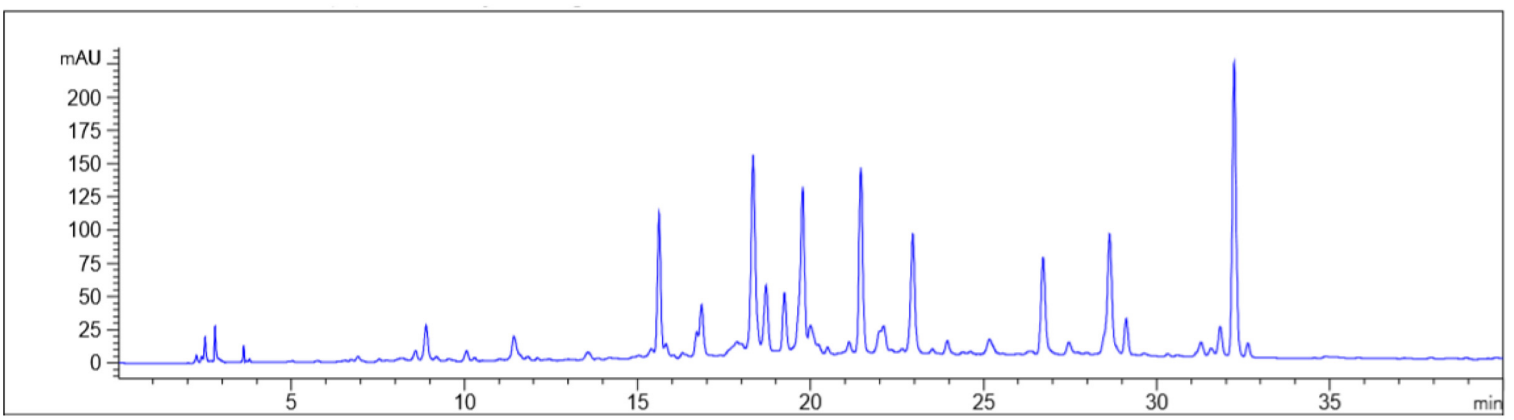

(C)

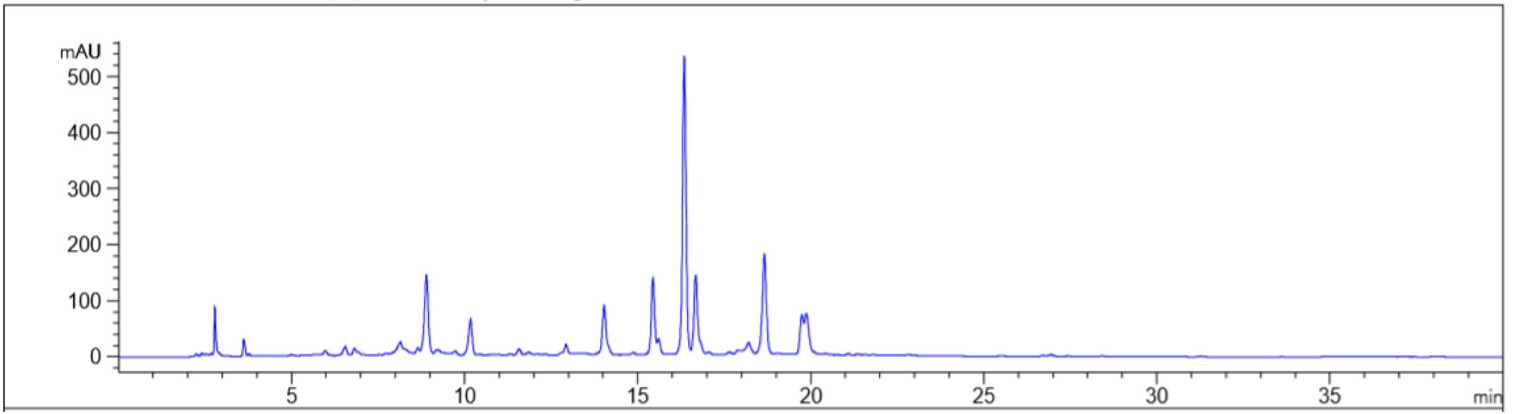

Fig. 3 HPLC chromatograms of quercetin (A), and the MeOH extracts of S. excelsus (B) and W. subsessilis (C)

lipids observed in diabetic individuals [15]. Accordingly, the polyol pathway is linked to the onset and progression of diabetic complications. Moreover, the inhibition of AR, the rate-limiting enzyme of the polyol pathway, prevents or arrests the progression of long-term complications associated with diabetes [16].

The ARI activity of the MeOH extracts of the flowers of $S$. excelsus and $W$. subsessilis was evaluated in this study. The results of the ARI assay are summarized in Table 1. Both $S$. excelsus and $W$. subsessilis exhibited potent ARI effects with $\mathrm{IC}_{50}$ values of 0.17 and $0.14 \mu \mathrm{g} / \mathrm{mL}$, respectively. $S$. excelsus extract showed similar and $W$. subsessilis extract exhibited better ARI activity than TMG $\left(\mathrm{IC}_{50}, 0.17 \mu \mathrm{g} / \mathrm{mL}\right)$. Lee et al. [17] reported that extracts of the leaves and stems of $W$. subsessilis exert three times more potent ARI effects than TMG. Nazaruk and BorzymKluczyk have reported that triterpenoid compounds exhibit potent ARI activities [18]. Interestingly, the $\mathrm{MeOH}$ extract of the aerial parts of $W$. subsessilis contains triterpenoids such as corosolic acid, which has been shown to exhibit strong ARI effects. Corosolic acid has a structure that is closely related to those of other known ARIs, such as ganoderic acid C2 and ganoderenic A
[19,20,21]. These related studies support that $W$. subsessilis contains ARIs. Although the ARI activity of $S$. excelsus has not been reported, previous reports have shown that it is abundant in phenolic ARIs, such as as quercetin, lutein, rutin, and scopoletin which are reported to be ARIs [12,22]. The results of this study demonstrate the potential use of $W$. subsessilis and $S$. excelsus as a potential source of ARIs. Further research to characterize the bioactive components of these plants will provide insights into their inhibitory activity against AR.

Scopolin, scopoletin, and quercetin were quantified using a reverse-phase HPLC system (Fig. 1). The analytical method displayed high resolution for the chromatographic separation of all three compounds as shown in Fig. 2 and 3. The calibration curve for each compound showed good linearity $\left(r^{2}=0.999\right)$ as seen in Table 2. Scopolin was present in $S$. excelsus and $W$. subsessilis at concentrations of 34.71 and $174.14 \mathrm{mg} / \mathrm{g}$ extract, respectively. Scopoletin was only detected in $S$. excelsus at $3.41 \mathrm{mg} / \mathrm{g}$ extract, whereas quercetin was not detected in both plants. Scopolin and its aglycone scopoletin are coumarins that were previously isolated from the flowers of $S$. excelsus and $W$. subsessilis [10,11]. These 
Table 2 Calibration curves of scopolin, scopoletin, and quercetin

\begin{tabular}{|c|c|c|c|c|}
\hline \multirow{3}{*}{ Compound } & \multirow{3}{*}{$\begin{array}{l}\text { Linear range } \\
(\mathrm{mg} / \mathrm{mL})\end{array}$} & \multicolumn{2}{|c|}{ Linear regression equation } & \multirow{3}{*}{$\begin{array}{c}\text { Correlation } \\
\text { coefficient } \\
\left(r^{2}\right)\end{array}$} \\
\hline & & \multicolumn{2}{|c|}{$\mathrm{Y}=\mathrm{aX} \pm \mathrm{b}$} & \\
\hline & & Slope (a) & Intercept (b) & \\
\hline Scopolin & $0.01-1.00$ & 2290.4 & 224.8 & 0.9990 \\
\hline Scopoletin & $0.01-1.00$ & 3958.9 & -61.6 & 0.9999 \\
\hline Quercetin & $0.01-1.00$ & 2513.3 & -75.5 & 0.9999 \\
\hline
\end{tabular}

$\mathrm{Y}=$ Peak area, $\mathrm{X}=$ Concentration of standard $(\mathrm{mg} / \mathrm{mL})$

$r^{2}=$ Correlation coefficient for three data points from the calibration curve

Table 3. Scopolin, scopoletin, and quercetin contents in the $\mathrm{MeOH}$ extracts of $S$. excelsus and $W$. subsessilis flowers

\begin{tabular}{cccc}
\hline \hline \multirow{2}{*}{ Sample } & \multicolumn{3}{c}{ Content (mg/g extract) } \\
\cline { 2 - 4 } & Scopolin & Scopoletin & Quercetin \\
\hline S. excelsus & $34.71 \pm 2.09$ & $3.41 \pm 0.03$ & ND \\
W. subsessilis & $174.14 \pm 0.01$ & ND & ND \\
\hline
\end{tabular}

Data are represented as mean $\pm \mathrm{SD}(\mathrm{n}=3) \mathrm{in} \mathrm{mg} / \mathrm{g}$ of the $\mathrm{MeOH}$ extracts of samples

$\mathrm{ND}=$ not detected

coumarins exhibit anti-inflammatory effects, and inhibit different enzymes, including nitric oxide synthase, prostaglandin synthase, monoamine synthase, and acetylcholinesterase [23,24]. Scopoletin has also been reported to exhibit moderate ARI activity [25]. Quercetin, a flavonoid that is commonly distributed in the flowers of different plant species, is widely-reported to exhibit strong antioxidant activity and ARI effects [8]. Hence, these compounds were analyzed in this study. To the best of our knowledge, this study is the first to describe an analytical method for the determination of all three compounds in S. excelsus and $W$. subsessilis.

The results of this study provide preliminary information regarding the ARI activities of the plants examined. Based on the results of our experiment, both $S$. excelsus and $W$. subsessilis can be potentially developed as natural therapies for managing diabetic complications.

Acknowledgments This research was supported by a grant from Seoul Science High School (2017), Republic of Korea.

\section{References}

1. Kador P (1988) The role of aldose reductase in the development of diabetic complications. Med Res Rev 8: 325-352

2. Brownlee M (2004) Biology and molecular cell biology of diabetic complications. Diabetes 54: 1615-1625

3. Robinson Jr. WG, Kador PF, Kinoshita JH (1983) Retinal capillaries: basement membrane thickening by galactosemia prevented with aldose reductase inhibitor. Science 221: 1177-1179

4. Engerman RL, Kern TS, Larson ME (1994) Nerve conduction and aldose reductase inhibition during 5 years of diabetes or galactosemia in dogs. Diabetologia 37: 141-144

5. Drel VR, Pacher P, Ali TK, Shin J, Julius U, El-Remessy AB, Obrosova IG (2008) Aldose reductase inhibitor fidarestat counteracts diabetesassociated cataract formation, retinal oxidative-nitrosative stress, glial activation, and apoptosis. Int J Mol Med 21: 667-676

6. Oates PJ, Mylari BL (1999) Aldose reductase inhibitors: therapeutic implications for diabetic complications. Expert Opin Investig. Drugs 8: 2095-2119

7. Niyeldt R, Van Nood E, Van Hoorn EC, Boelens P, Van Norren K, Van Leeuwen PAM (2001) Flavonoids: a review of probable mechanism of action and potential applications. Am J Clin Nutr 74: 418-425

8. Varman SD, Mikuni I, Kinoshita JH (1975) Flavonoids as inhibitors of lens aldose reductase. Science 188: 1215-1216

9. Shin HT, Yoo ST, Kim BD, Yi MH (2010) Dispersion of vascular plant in Mt. Huiyangsan, Korea. J Kor Nature 3: 1-10

10. Nam JH, Choi SJ, Lee KR (2004) Phytochemical constituents of Synurus excelsus. Kor J Pharmacogn 35: 116-121

11. Thuong PT, Na MK, Su ND, Seong RS, Lee YM, Sok DE, Bae KH (2005) Inhibitory effect of coumarins from Weigela subsessilis on low density lipoprotein oxidation. Biol Pharm Bull 28: 1095-1097

12. Lee J, Ryu H-S, Rodriguez JP, Lee S (2017) Aldose reductase inhibitory activity of quercetin from the stems of Rhododendron mucronulatum for. albiflorum. J Appl Biol Chem 60: 29-33

13. Hayman S, Kinoshita JJ (1965) Isolation and properties of lens aldose reductase. Biol Chem 240: 877-882

14. Brownlee M (2001) The pathobiology of diabetic complications: a unifying mechanism. Nature 414: 813-820

15. Tang WH, Martin K, Hwa J (2012) Aldose reductase, oxidative stress, and diabetic mellitus. Front Pharmacol 3: 1-8

16. Grewal AS, Bhardwaj S, Pandita D, Lather V, Sekhon BS (2016) Update on aldose reductase inhibitors for management of diabetic complications and non-diabetic diseases. Mini-Rev Med Chem 16: 120-162

17. Lee YM, Kim YS, Kim JH, Kim JS (2011) Screening of Korean herbal medicines with inhibitory effect on aldose reductase. Kor J Pharmacogn 42: $161-168$

18. Nazaruk J, Borzym-Kluczyk M (2015) The role of triterpenes in the management of diabetes mellitus and its complications. Phytochem Rev 14: 675-690

19. Lee MS, Lee CM, Cha EY, Thuong PT, Bae KH, Song IS, Noh SM, Sul JY (2010) Activation of AMP-activated protein kinase on human gastric cancer cells by apoptosis induced by corosolic acid isolated from Weigela subsessilis. Phytother Res 24: 1857-1861

20. Na M, Thuong PT, Hwang IH, Bae K, Kim BY, Osada H, Ahn S (2010) Protein tyrosinase 1B inhibitory activity of 24-norursane triterpenes isolated from Weigela subsessilis. Phytother Res 24: 1716-1719

21. Rao AR, Veeresham C, Asres K (2013) In vitro and in vivo inhibitory activities of four Indian medicinal plant extracts and their major components on rat aldose reductase and the generation of advanced glycation endproducts. Phytother Res 27: 753-760

22. Lee K, Yang MC, Lee KH, Choi SY, Lee KR (2007) Phenolic constituents from the flowers of Synurus excelsus. Kor J Pharmacogn 38: 181-186

23. Pan R, Dai Y, Gao X, Xia Y (2009) Scopolin isolated from Erycibe obtusifolia Benth stems suppresses adjuvant-induced rat arthritis by inhibiting inflammation and angiogenesis. Int $\mathrm{J}$ Immunopharmacol 9: 859-869

24. Rollinger JM, Hornick A, Langer T, Stuppner H, Prast H (2004) Acetylcholinesterase inhibitory activity of scopolin and scopoletin discovered by virtual screening of natural products. J Med Chem 47: 6248-6254

25. Jung HA, Islam MDN, Kwon YS, Jin SE, Son YK, Park JJ, Sohn HS, Choi JS (2011) Extraction and identification of three major aldose reductase inhibitors from Artemisia montana. Food Chem Toxicol 49: 376-384 